\title{
National Ignition Facility Configuration Management Plan
}

S.G. Cabral, T.L. Moore

October 10, 2002

U.S. Depertment of Energy

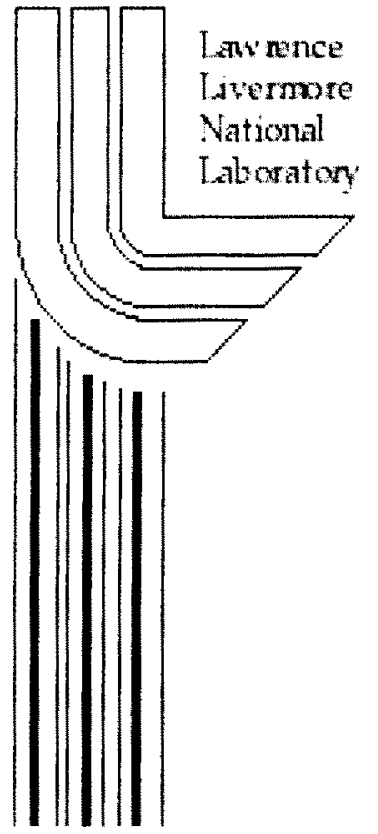




\section{DISCLAIMER}

This document was prepared as an account of work sponsored by an agency of the United States Government. Neither the United States Government nor the University of California nor any of their employees, makes any warranty, express or implied, or assumes any legal liability or responsibility for the accuracy, completeness, or usefulness of any information, apparatus, product, or process disclosed, or represents that its use would not infringe privately owned rights. Reference herein to any specific commercial product, process, or service by trade name, trademark, manufacturer, or otherwise, does not necessarily constitute or imply its endorsement, recommendation, or favoring by the United States Government or the University of California. The views and opinions of authors expressed herein do not necessarily state or reflect those of the United States Government or the University of California, and shall not be used for advertising or product endorsement purposes.

This work was performed under the auspices of the U. S. Department of Energy by the University of California, Lawrence Livermore National Laboratory under Contract No. W-7405-Eng-48.

This report has been reproduced directly from the best available copy.

Available electronically at http://www.doc.gov/bridge

Available for a processing fee to U.S. Department of Energy

And its contractors in paper from

U.S. Department of Energy

Office of Scientific and Technical Information

P.O. Box 62

Oak Ridge, TN 37831-0062

Telephone: (865) 576-8401

Facsimile: (865) 576-5728

E-mail: reports@adonis.osti.gov

Available for the sale to the public from

U.S. Department of Commerce

National Technical Information Service

5285 Port Royal Road

Springfield, VA 22161

Telephone: (800) 553-6847

Facsimile: (703) 605-6900

E-mail: orders@ntis.fedworld.gov

Online ordering: http://www.ntis.gov/ordering.htm

OR

Lawrence Livermore National Laboratory

Technical Information Department's Digital Library

http://www.llnl.gov/tid/Library.html 
LAWRENCE LIVERMORE NATIONAL LABORATORY

University of California - Livermore, California - 94550 


\section{National Ignition Facility Configuration Management Plan Revision 2}
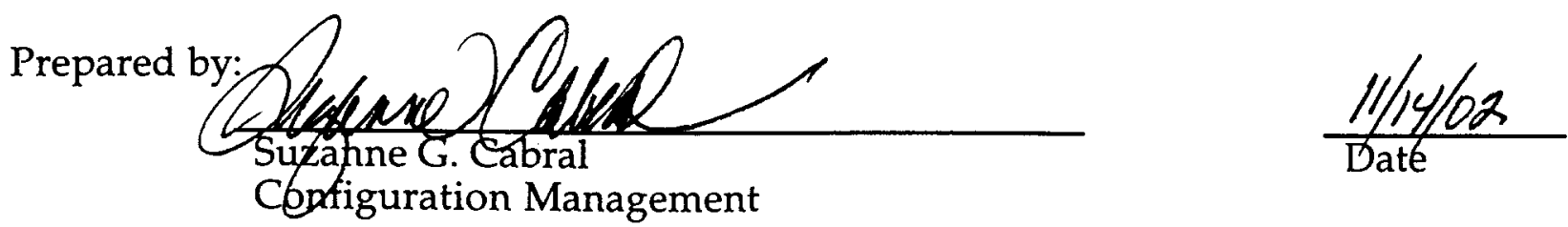

Reviewed by:
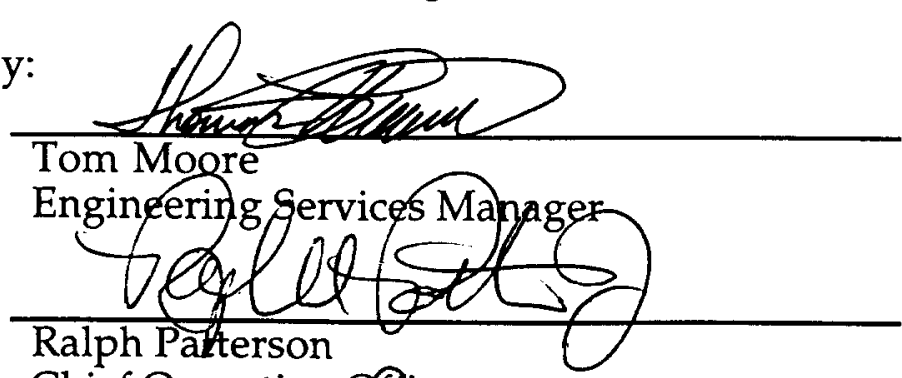

Chief Operating Qffticer
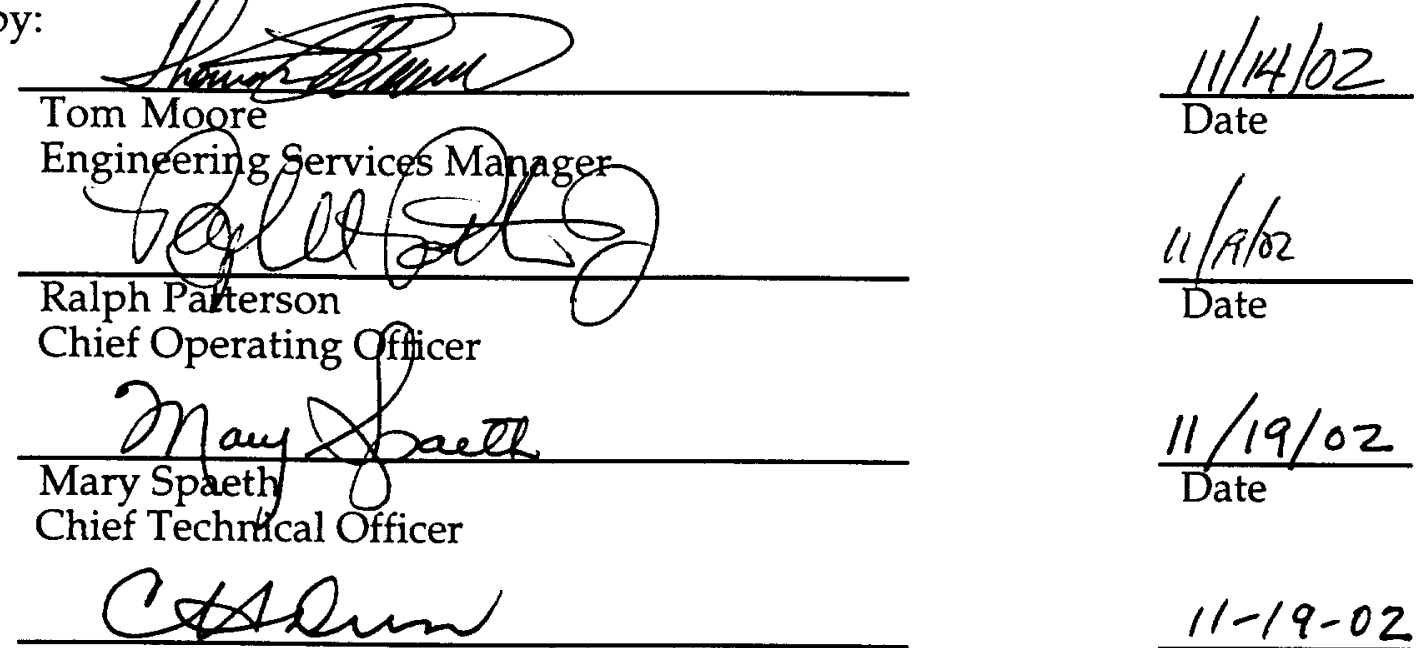

C. Dun

Quality Assurance Manager

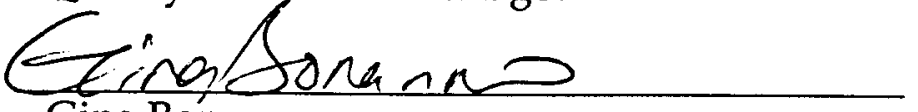

Gina Bonnano

Assoctate Project Manager AIR

$\frac{11 / 19 / 02}{\text { Date }}$

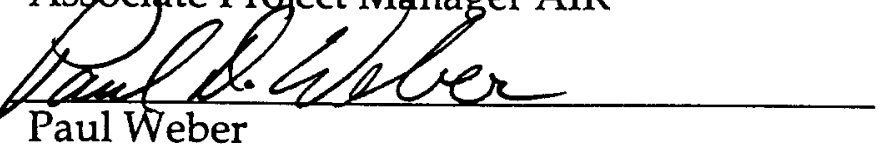

Associate Project Manager Production Control

$\frac{11-19-02}{\text { Date }}$

$11-19-02$

Date

$\frac{11 / 20 / 02}{\text { Date }}$

Approved by:

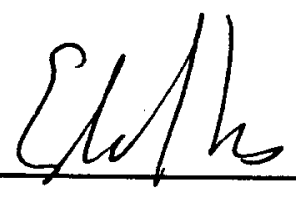

Ed Moses

NIF Laboratory Project Manager

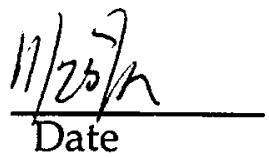




\section{Table of Contents}

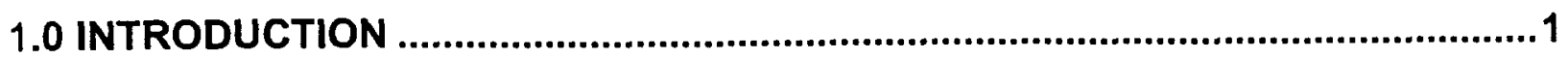

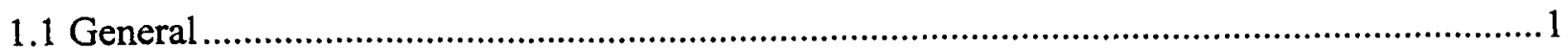

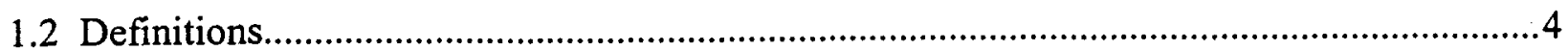

2.0 ORGANIZATION

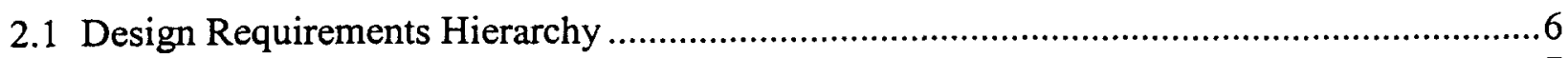

2.2.1 Involved Personnel......................................................................................

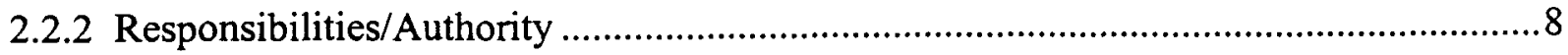

3.0 TECHNICAL BASELINE IDENTIFICATION.......................................................11

3.1 Functional Requirements Baseline.........................................................................11

3.2 Technical Requirements Baseline .........................................................................11

3.3 Design Requirements Baseline ............................................................................ 12

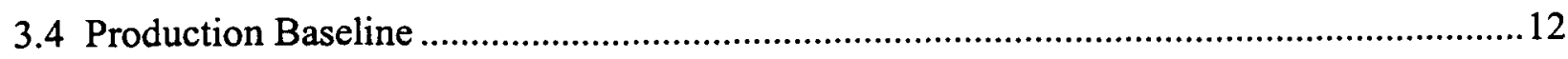

3.5 As-Built Configuration Baseline.......................................................................... 13

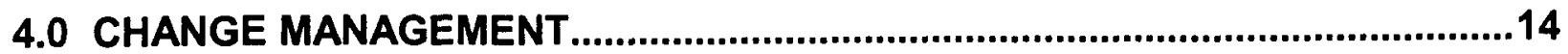

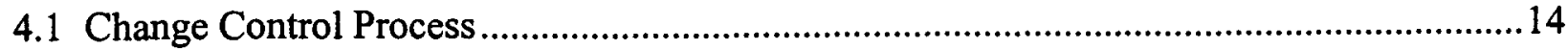

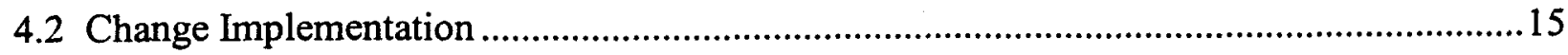

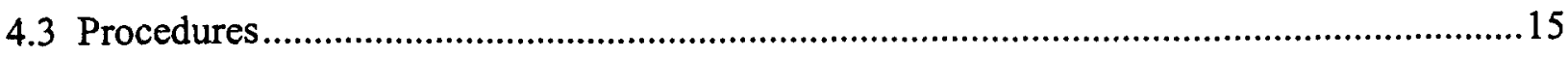

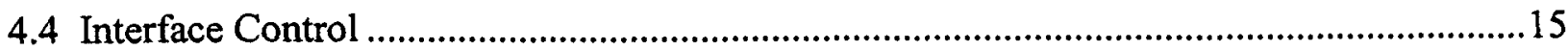

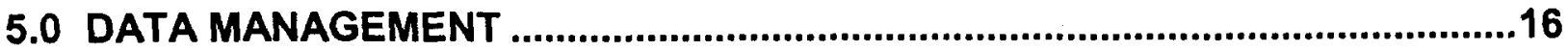

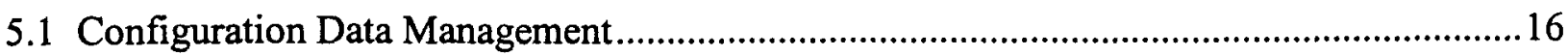

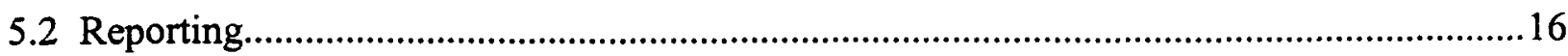

6.0 ASSESSMENTS AND VALIDATION........................................................17

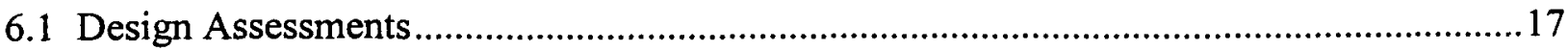

6.2 Physical Configuration Assessments ...................................................................... 17

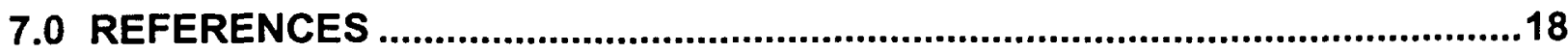




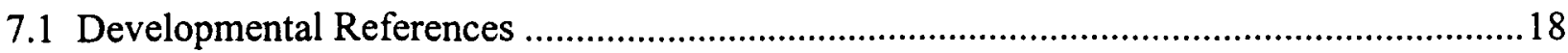

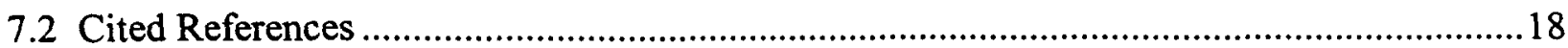




\section{List of Figures}

Figure 1. Flowchart for the overall configuration management process...........................

Figure 2. Hierarchy of configuration management documents.........................................

Figure 3. NIF configuration management organization. ................................................... 8

Figure 4. NIF Project technical baselines. ........................................................................ 11

\section{List of Acronyms}

ACD
APE/L
BCCB
BCP
CCB
CDR
CMP
DOE
ECR
ECO
ICD
NIF
PCM
PDMS
QA
RFI
SDR
SSDR
SI
TEC
TPC
WBS

$A C D$

$\mathrm{BCCB}$

$\mathrm{BCP}$

CCB

CDR

CMP

DOE

ECR

ECO

ICD

NIF

PDMS

QA

SDR

SSDR

TEC

WBS
Advanced Conceptual Design

Associate Project Engineer/Leader

Baseline Change Control Board

Baseline Change Proposal

Configuration Control Board

Conceptual Design Report

Configuration Management Plan

U.S. Department of Energy

Engineering Change Request

Engineering Change Order

Interface control document

National Ignition Facility

Project Control Manual

Product Data Management System

Quality assurance

Request for information

System design requirement

Software subsystem design requirement

System integration

Total estimated cost

Total Project cost

Work breakdown structure 


\subsection{Introduction}

\subsection{General}

This Configuration Management Plan (CMP) describes the technical and administrative management process for controlling the National Ignition Facility (NIF) Project configuration. The complexity of the NIF Project (i.e., participation by multiple national laboratories and subcontractors involved in the development, fabrication, installation, and testing of NIF hardware and software, as well as construction and testing of Project facilities) requires implementation of the comprehensive configuration management program defined in this plan. A logical schematic illustrating how the plan functions is provided in Figure 1. A summary of the process is provided in Section 4.0, Configuration Change Control. Detailed procedures that make up the overall process are referenced.

This CMP is consistent with guidance for managing a project's configuration provided in Department of Energy (DOE) Order 430.1, Guide PMG 10, Project Execution and Engineering Management Planning.

Configuration management is a formal discipline comprised of the following four elements:

- Identification - defines the functional and physical characteristics of a Project and uniquely identifies the defining requirements. This includes selection of components of the end product(s) subject to control and selection of the documents that define the project and components.

- Change management - provides a systematic method for managing changes to the project and its physical and functional configuration to ensure that all changes are properly identified, assessed, reviewed, approved, implemented, tested, and documented.

- Data management - ensures that necessary information on the project and its end product(s) is systematically recorded and disseminated for decision-making and other uses. Identifies, stores and controls, tracks status, retrieves, and distributes documents.

- Assessments and validation - ensures that the planned configuration requirements match actual physical configurations and approved changes are implemented according to the change requirements documents. 
The configuration management process, as with other management controls, is applicable to the NIF Project in a graded manner consistent with the significance of Project elements. Those elements related to public safety, the environment, or the successful completion of the Project mission, undergo more rigorous review considerations than those that support less important facility functions.

The NIF Project configuration management process comprises a collection of controls for managing requirements, design, development, fabrication, installation, construction, inspection, and acceptance-testing and operational-testing activities. These controls are a subset of the Project's implementing procedures contained in the Project Control Manual, ${ }^{1}$ eventually extending to Project-approved subcontractors' plans and procedures. These controls include prescribed performance standards for the activities and the necessary verification actions to assure compliance with the standards. They provide the means to identify, control, verify, and maintain the Project configuration. 


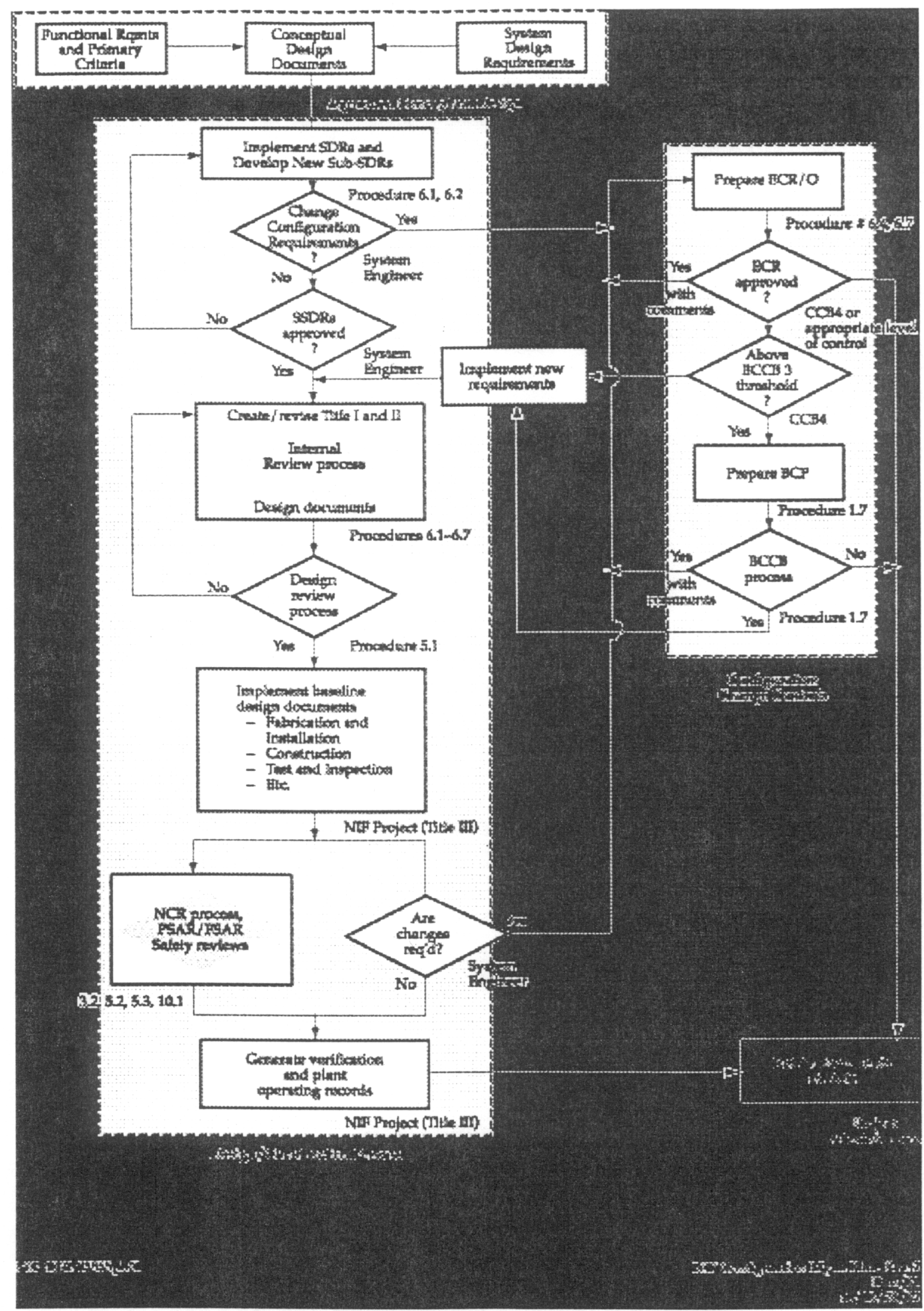

Figure 1. Flowchart for the overall configuration management process. 
This CMP describes the logic that links those procedures related to strict maintenance of the Project configuration, from the earliest establishment of approved primary criteria and functional requirements, to the completion and documentation of installation, acceptance/operational testing, as-built verification, and operating records.

\subsection{Definitions}

Baseline Change Control Board (BCCB) 2,3 - A multidisciplinary group of Project management representatives, chartered to determine the merit of incorporating proposed changes to Project baselines by ensuring the proper definition, coordination, evaluation, and disposition of all BCPs within their jurisdiction. There are three BCCBs identified for the NIF Project, the lowest of which (Level 3) acts for the Laboratory's Project team.

Baseline Change Proposal (BCP) ${ }^{3}$ - The document (form) prepared to propose a change to any Project baseline and to provide a complete description of the proposed change and its resulting impacts to other baselines. When the technical baseline is involved, BCPs are supported by information contained in conditionally approved ECRs. The BCP Request form includes a Record of Decision.

Change Control Threshold2,4 A level or amount of change, corresponding to a designated level of approval authority. There are six quantitative threshold levels identified for the NIF Project. These levels correspond to the levels of approval authority. Changes below the lowest level of baseline approval authority (Level 3 Change Control Board) are processed as ECRs by the responsible technical authority (Level 6 through 4).

Configuration Management ${ }^{3}-$ An integrated management system designed to maintain the relationship between requirements, physical/functional configurations, and documentation. This involves the systematic evaluation, coordination, approval, documentation, implementation, and verification of approved changes to the NIF Project configuration (technical baseline) after having formally identified the baseline. The configuration of the NIF Project is assured by this process, which involves a series of project controls that establish and maintain consistency among design requirements, the physical configuration, and project documentation. These controls involve verification of consistency among the following:

- Project requirements and criteria.

- Design and design changes.

- Hardware fabrication and installation.

- Construction.

- Software.

- Inspections and acceptance tests.

- Document status.

Cost Baseline - The Project budget developed from cost estimates made after the technical baseline has been established and time-phased in accordance with the Project 
schedule. The cost baseline is integrated with the technical and schedule baselines. Once approved by the DOE, the cost baseline is subject to formal change control, implemented by the Project baseline change control procedure. 2,3

Engineering Change Request (ECR) ${ }^{4}-$ The form used to initiate a request or proposal for changing any NIF technical design requirement previously released under configuration management. Properly completed the ECR form contains sufficient information to identify the technical scope of the proposed change and formulate an implementation plan.

Level 4 Change Control Board (CCB $)^{4}-$ A multidisciplinary standing committee of technical management representatives at Level 4 chartered to review and recommend the approval or disapproval of ECRs.

Level 5 Change Control - A multidisciplinary committee of technical management representatives chartered by the Level $4 \mathrm{CCB}$, as required, to review and recommend approval of ECRs prior to their submittal.

Schedule Baseline-The time-phased plan and logical sequence of interdependent activities, milestones, and events required to successfully complete the Project. The schedule baseline is integrated with the technical and cost baselines. Once approved by the DOE, the schedule baseline is subject to formal change control, implemented by the Project baseline change control procedure. 2,3

Technical Baseline - The Project configuration as identified in documents formally designated and approved by the NIF Laboratory Project Manager and the DOE. Once approved by the DOE, the NIF Functional Requirements and Primary Criteria in the Conceptual Design Report ${ }^{5}$ (CDR) became the initial Project technical baseline, which is then subject to formal change control, implemented by the Project baseline change control procedure. 2,3 This baseline, plus approved changes, constitutes the project work scope. The physical aspects of the technical baseline are developed in greater detail during each project design phase (i.e., Advanced Conceptual Design, Title I and II). These are eventually finalized as engineering design documents that provide directions for construction, fabrication, installation, and testing of the Project facilities and equipment.

Title III Engineering ${ }^{6}$ - The phase that begins at the initiation of procurement action, i.e., the submission of requisitions, extends through fabrication/construction, and continues through the completion of construction and equipment acceptance tests. It includes field engineering, problem resolution, configuration control, and documentation maintenance. The technical staff includes those required to maintain all engineering design records and as-built drawings at Project completion. The work includes the revision of existing design documentation and the generation of any new design documentation required as construction proceeds, engineering analysis to evaluate proposed design changes, and engineering support for inspection, assembly, installation, and testing. 


\subsection{Organization}

\subsection{Design Requirements Hierarchy}

The hierarchy of requirements governing the management of the NIF Project configuration is illustrated in Figure 2. The requirements define the flow down of design criteria and control the baseline configuration of the NIF Project from its inception, through its operation. Each of these requirement types is controlled at varying levels of management authority. For example, the uppermost tier of requirements contain mission-related commitments for the Project and regulations that apply to the work involved. These requirements cannot be changed without the approval of the highest levels of authority: the DOE Acquisition Executive (Level 0) or the National Nuclear Security Administration (NNSA) Deputy Administrator for Defense Programs at DOE Headquarters (Level 1). Lower tiers contain more detailed requirements (ultimately the actual directions for construction, installation, and testing). These documents cannot be changed without the approval of a BCCB whose authority is established corresponding to the significance of the proposed change.

There are three Baseline Change Control Boards (BCCBs) below the Acquisition Executive level (which is Level 0):

- BCCB 1-NNSA Deputy Administrator for Defense Programs.

- BCCB 2-DOE Office of the NIF.

- BCCB 3-NIF Laboratory Project Manager.

The membership of these boards and their change authority and protocol are addressed in the Project Execution Plan ${ }^{2}$ (PEP) and prescribed in NIF Procedure 1.7, Project Change Control. ${ }^{3}$ The Boards deal with any deviation that affects the approved NIF technical performance and cost or schedule thresholds established for them. The authority of the BCCB 3 (NIF Laboratory Project Office level) includes the following:2

- Any change in system design requirements (SDRs) that affect system performance.

- Changes to Level 2 milestones of less than six months.

- Changes from Level 3 schedule milestones in excess of six months.

- Changes less than $+\$ 10 \mathrm{M}$ that do not affect total estimated cost (TEC)/total Project cost (TPC).

- Changes requiring contingency allocations up to $\$ 10 \mathrm{M}$. 


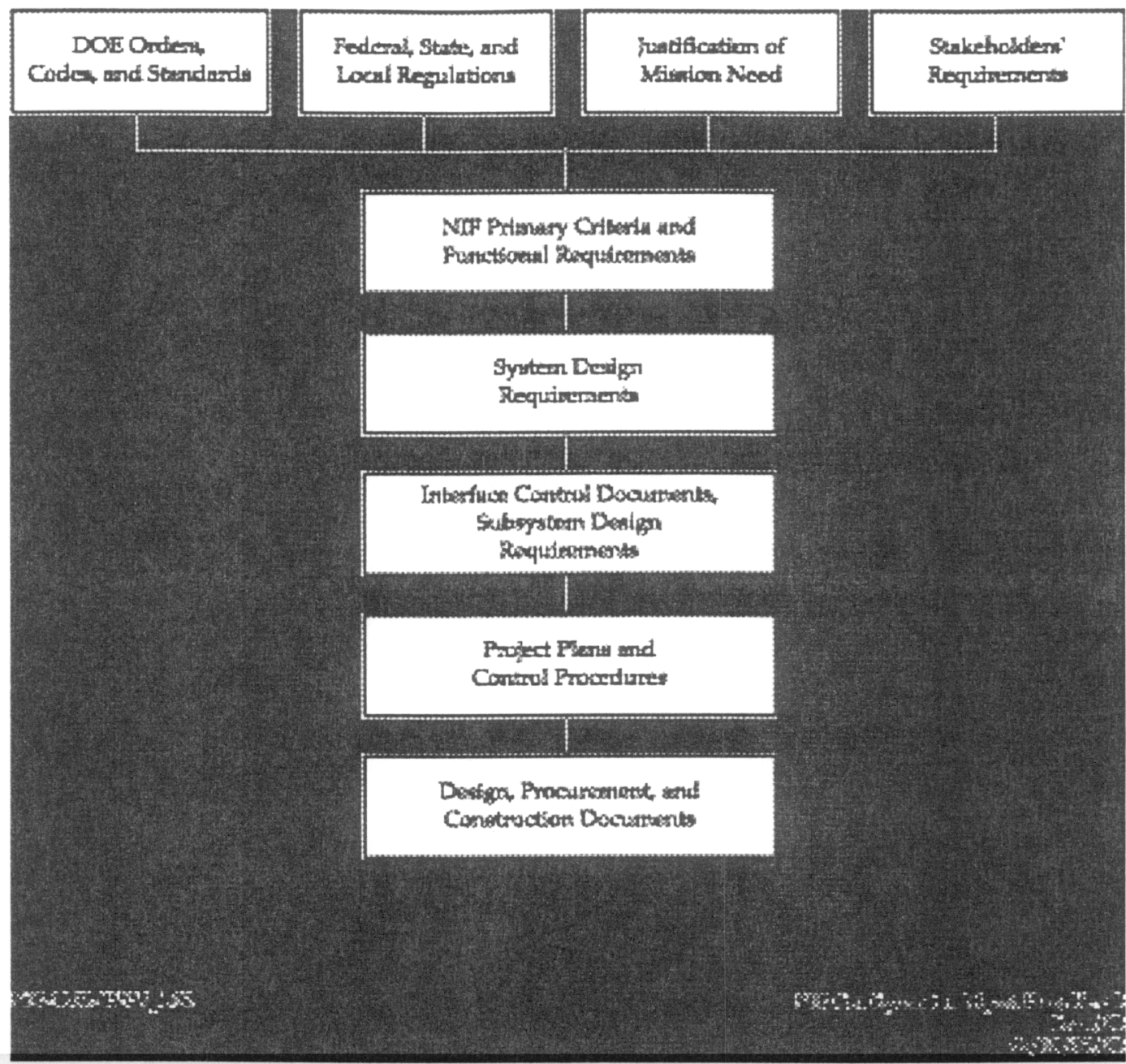

Figure 2. Hierarchy of configuration management documents.

Changes with impacts below (smaller than) the BCCB 3 thresholds are processed within the Project by the responsible technical authority as identified by the ECR process $^{4}$ and the NIF Project Control Procedure 1.7, Baseline Change Control. ${ }^{3}$

\subsection{Configuration Management Organization}

\subsubsection{Involved Personnel}

The management positions shown in Figure 3 have authoritative roles in managing the Project configuration and are accountable for actions in the change control process. These positions include those with responsibilities for BCCBs at levels 3, 2, 1, and 0, and changes below the BCCB threshold levels, which are processed as ECRs. 


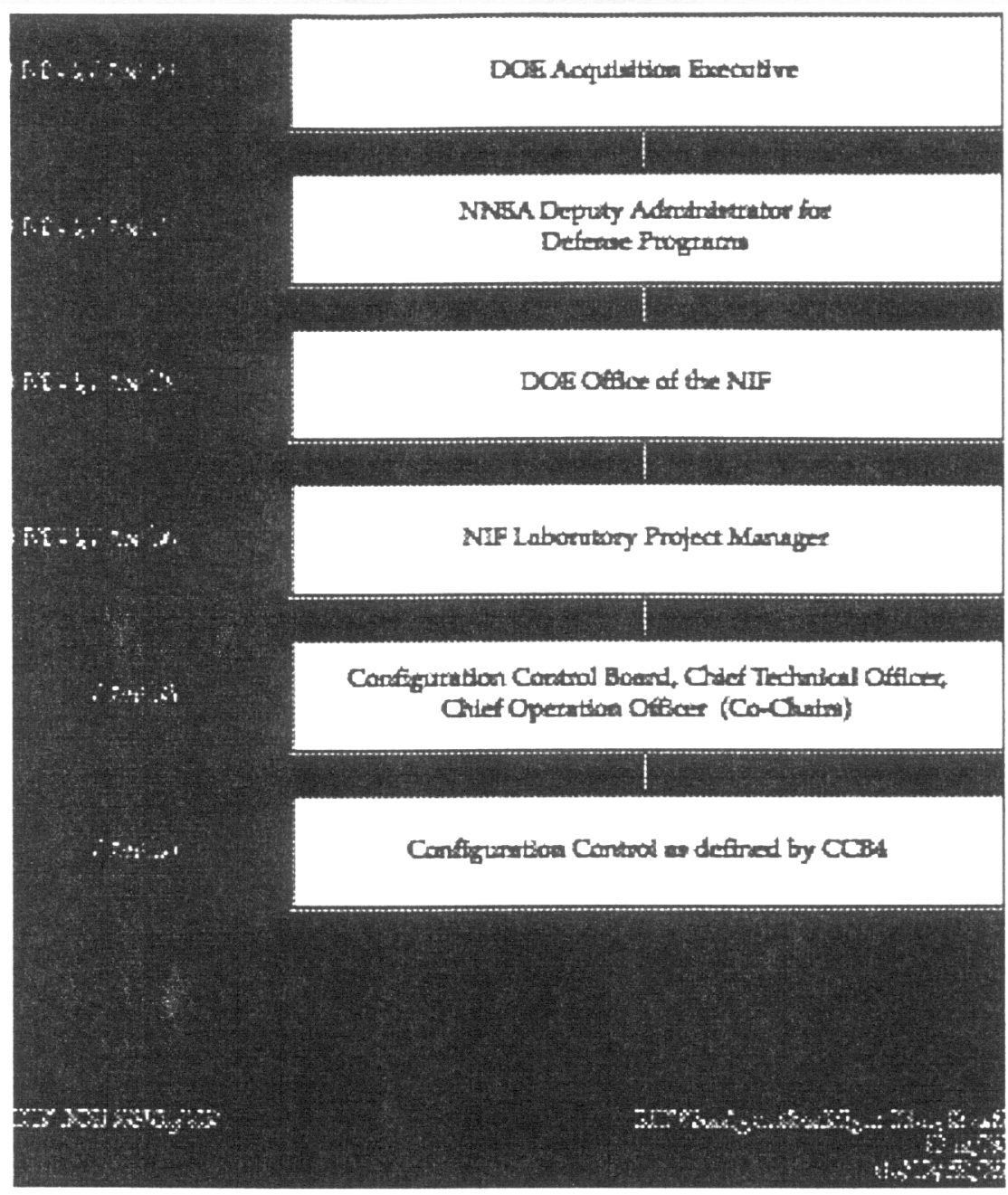

Figure 3. NIF configuration management organization.

\subsubsection{Responsibilities/Authority}

The responsibilities for managing the Project's technical baseline are documented in NIF Procedure 6.4. ${ }^{4}$ These responsibilities are summarized below in the order of executive authority, beginning at the highest DOE level. Technical baseline control authority includes collective expertise provided by BCCBs that also are concerned with the cost and schedule implications of technical changes. Cost and schedule control are not specifically addressed in this document. However, technical baseline changes often involve cost and schedule impacts that require $\mathrm{BCCB}$ actions.

All changes affecting cost and/or schedule baselines are requested and dispositioned on NIF BCP forms. ${ }^{3}$

Level 0 BCCB - The DOE Acquisition Executive is responsible for authorizing the disposition of any proposed change that would deviate from the Project mission described in the Justification of Mission Need. ${ }^{7}$ 
Level 1 BCCB - The DOE NNSA Deputy Administrator for Defense Programs is responsible for authorizing disposition of any proposed change that would deviate from the Primary Criteria and selected Functional Requirements.

Level 2 BCCB - The Director, Office of the NIF, is responsible for authorizing disposition of any proposed change that would deviate from the Functional Requirements other than those selected for Level 1 control.

Level 3 BCCB - The NIF Laboratory Project Office is responsible for authorizing disposition of any proposed change in the System Design Requirements (SDRs) that affect system performance.

Level 4 Change Control Board (CCB4) - The CCB4 is responsible for reviewing changes that affect major layouts, major interface drawings, and related high-level specifications under configuration control and changes with a cost and/or schedule impact. They review for technical adequacy and accuracy, safety and environmental effects, cost and schedule impacts, operability, reliability, maintainability, manufacturability, inspectability, testability, and overall acceptability. The CCB4 assists technical managers by recommending approval or disapproval of design changes to NIF systems and components that would deviate from approved requirement documents previously released under configuration control. The CCB4 endorses and forwards ECRs that exceed Level 4 thresholds to BCCB 3. Membership of the Level CCB4 includes personnel such as: effected technical representatives; cost and schedule control representatives; and representatives of safety, environment, operations, maintenance, and quality assurance; all pursuant to the nature of the change issues.

Level 5 Change Control Authority - Prior to their submittal as formal ECRs, the Level 5 change authority (if assigned) is responsible for reviewing changes to determine if all interfaces, impacts, and costs have been assessed and noted.

Level 6 (Associate Project Engineer/Leader) - The Responsible Engineer is responsible for approving design changes to drawings, specifications, and other design media under configuration management that do not change SDRs, subsystem design requirements (SSDRs), interface control drawings (ICDs), major layouts, major interface drawings, and related high-level specifications and have no cost and/or schedule input. These changes generally occur at WBS Level 4 or lower.

Configuration Manager - The Configuration Manager reports to Engineering Services Manager and is responsible for the following:

- Developing and documenting methods and instructions for Configuration Management, including management of configuration data on a day-to-day basis.

- Implementing the overall configuration management process.

- Maintaining this CMP.

- Maintaining CM data management for the Project. 


\section{Associate Project Engineers (APEs) or Leader (APL), Conventional Facility Construction Manager, Conventional Facility Design Manager, and System} Engineers - These line managers are responsible for participation, review, input, and/or approval of design reviews of NIF systems and for ensuring compliance with this CMP within their areas of authority. They are also responsible for participating on CCB4, when appropriate, and for authorizing disposition of any approved changes within their purview.

Systems Integration Manager - The Systems Integration (SI) Manager is responsible for controlling system interfaces by participation, review, and input to design reviews of NIF systems to assure that interfaces between and among systems are properly addressed and accommodated. The SI Manager is also responsible for monitoring the progression and development of system designs as details are added, potentially affecting other systems, and for reviewing and providing input to proposed technical changes involving system interfaces. The SI Manager is also responsible for ensuring compliance to this CMP within his/her area of technical accountability.

Principal Subcontractors - Architect-Engineering firms, Engineering Services organizations, Construction Management firms, and other vendors under subcontract to the NIF Project are responsible for directing their technical resources, as directed by subcontract, and for implementing SDRs, approving ECRs, and controlling system configurations in accordance with the NIF Quality Assurance Program Plan. ${ }^{8}$ Subcontractors may request design changes and clarifications via Requests for Information (RFIs). 


\subsection{Technical Baseline Identification}

The NIF Project technical baseline is developed during each stage of the design process as the sophistication of the design increases and details are added. This progressive maturity of the technical baseline is illustrated in Figure 4.

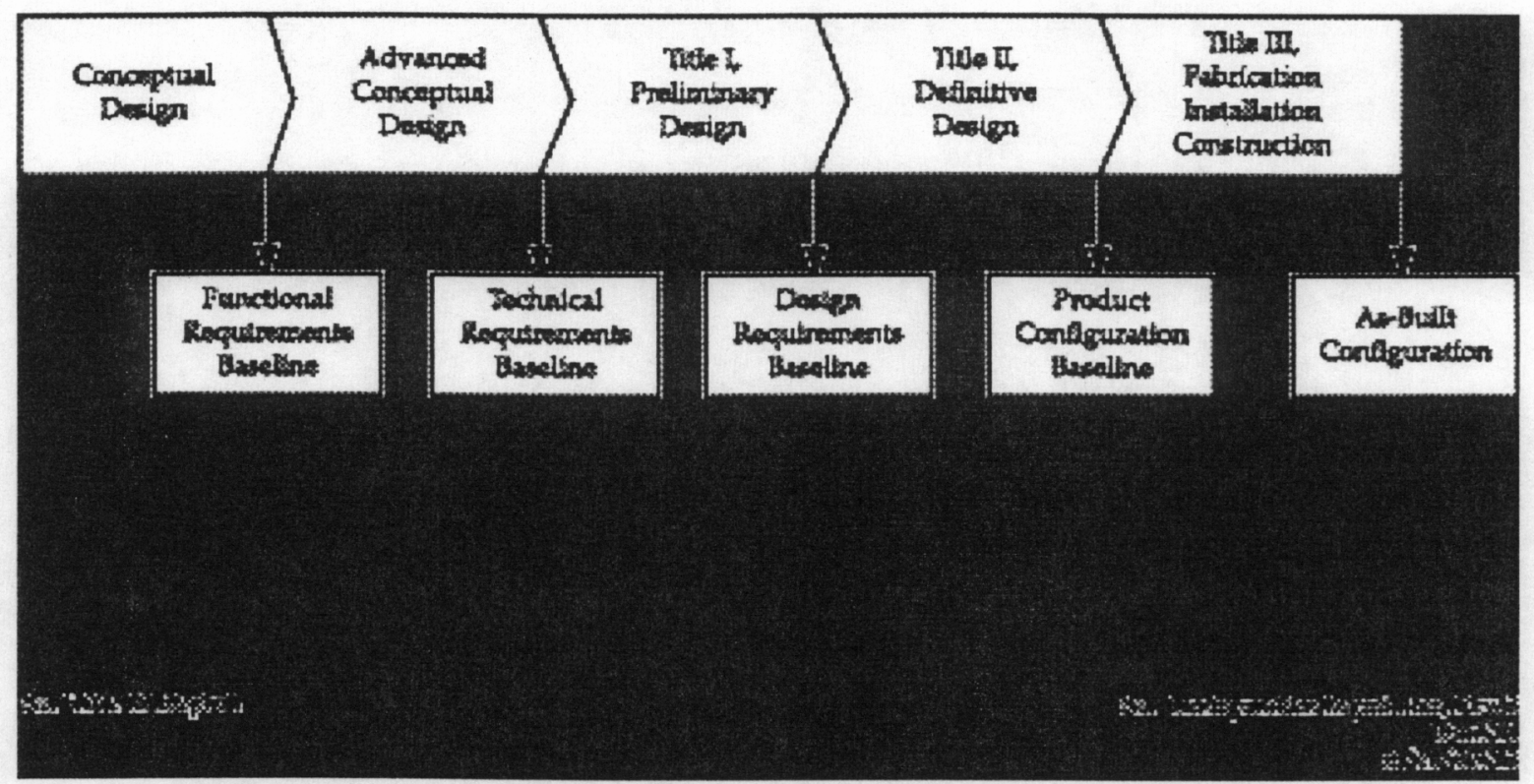

Figure 4. NIF Project technical baselines.

\subsection{Functional Requirements Baseline}

The Functional Requirements baseline is defined by information contained in the PEP. ${ }^{2}$ It is the initial Project technical baseline, distinguished by the formal establishment of a firm NIF design basis documented in the following:

- Justification of Mission Need.

- Functional Design Requirements and Primary Criteria.

- System Design Requirements (SDRs).

- Interface Control Documents (ICDs).

- Safety and environmental documents.

\subsection{Technical Requirements Baseline}

The Technical Requirements baseline is established by the conceptual design and any approved changes. The detail in the Conceptual Design Report ${ }^{5}(\mathrm{CDR})$ is characteristic of this early baseline. Drawings depict the Project configuration in conceptual terms and are developmental in nature. 
The Advanced Conceptual Design ( $A C D$ ) addresses additional study required to identify unresolved issues and increase confidence in system designs described in the $\mathrm{CDR}$ and to further investigate selected topical areas, such as direct-drive beam configuration, building structure and configuration, spatial filter length, and beam expansion. The Technical Requirements baseline is characterized by the CDR plus the $A C D$ results. It forms the basis for Title I (preliminary) design.

To assure that this baseline is consistent with the commitments established in the $C D R$, a design review is conducted at the conclusion of the ACD.

\subsection{Design Requirements Baseline}

The Design Requirements baseline is defined by the aggregation of the CDR, ACD, and Title I Design documents. This baseline is established at the completion of Title I Design and is the basis for Title II (definitive) Design. At this stage, preliminary design translates the functions and requirements from the conceptual phase into preliminary drawings and outline specifications, preliminary cost estimates, and scheduling for project completion. Preliminary design identifies long lead procurement items and provides analysis of risks associated with continued project development. The configuration defined by the preliminary drawings and outline specifications is represented by the Design Requirements Baseline with the following content:

- the physical systems are identified.

- the boundaries and interfaces for each physical system are identified.

- the major components for the physical systems are identified and defined.

- the functions and requirements, performance criteria, and constraints established in the conceptual phase are allocated to the respective physical systems and major components.

The Design Requirements baseline is formally entered into the NIF PDM system through the approval and release of design requirements and documents as they are developed and finalized.

\subsection{Production Baseline}

The Production Baseline represents the output of the detailed design portion of the execution phase and forms the basis for construction, procurement, manufacturing, installation, and startup of the facility. It is the final design baseline and is established at the completion of design reviews of the output products of the NIF Project's Title II design effort on all systems. The functions and requirements from the conceptual phase and the design requirements from preliminary design, as applicable, are expanded to include the detail required to construct the systems and components of NIF. This 
baseline includes approved design requirements, detailed drawings and specifications, calculations, quality assurance procedures, test instructions, and operating and maintenance information.

The Production Baseline contains all the design information needed for fabrication, installation, construction, testing, and checkout of all facilities and equipment. At this stage, particular attention is given to shop and field conditions that could cause changes in the baseline, to the impact of changes to system interfaces, and to the strict configuration control of documentation that will be used to reflect the final configuration of all Project systems.

\subsection{As-Built Configuration Baseline}

The As-Built Configuration Baseline is defined by the full compilation of documentation that reflects the final configuration of all Project systems after the construction, manufacturing, and installation processes have been completed (Title III engineering). This baseline forms the basis for the hardware configuration/site registry database and is used as the hardware configuration baseline during operations and maintenance functions. In addition to the documentation contained in the Production Baseline, this baseline includes acceptance procedures and inspection data that validates the configurations meet the original design criteria.

The As-Built Baseline contains all the design information needed to provide traceability and accountability for NIF's configuration identification and change control functions. The detailed design documents established in the Production Baseline are used to establish the As-Built Configuration Baseline as follows:

- All changes occurring to the Production Baseline during construction or fabrication are approved and reflected in the As-Built Configuration Baseline.

- All changes occurring to the Production Baseline during the operations phase after system turnover are approved and reflected in the As-Built Configuration Baseline. 


\subsection{Change Management}

The Configuration Management Program is an integrated management system for establishing and then controlling and documenting the NIF Project's technical baselines and all approved changes. It is established and controlled in accordance with this CMP and detailed in the NIF Project Control Manual. ${ }^{1}$ The process is illustrated in Figure 1 and described in the following sections.

In this process, appropriate consideration is given to the effects of technical change upon the Project cost and schedule baselines through formal engineering change control and $\mathrm{BCCB}$ and $\mathrm{CCB} 4$ action, according to established threshold levels. 2,3

\subsection{Change Control Process}

Changes to approved documents under configuration management are controlled according to the ECR and BCP processes, 3,4 which ensure the systematic review of the technical accuracy, adequacy, and cost and schedule impacts of a proposed change with respect to change control thresholds. Approval of an ECR includes any changes in the NIF configuration. When any baseline threshold is met or exceeded by a proposed change, a BCP is generated and submitted to the Level 4 BCCB for action.

The design of the NIF is accomplished incrementally $9-11,6$ according to plans and schedules for each unit of work scope established in the NIF Project work breakdown structure (NWBS). Formal design reviews are performed at the completion of each design phase to ensure that design requirements are met and that baseline integrity is maintained. Upon acceptance of the Title I Design documents, signified by completion of the Title I Design review, the Design Requirements baseline is established. Upon approval of Title II Design, the Production Baseline is established. Competitive bids are obtained on the basis of the Title II drawings and specifications, and procurement subcontracts are established.

During the course of building the NIF, changes may be needed as a result of deviating conditions that arise in the field or on the production line. Whether the changes are necessitated by design oversight, unplanned events (e.g., workforce strikes, severe weather), or any other reason, the changes are controlled by the ECR process. The Project work accomplished in this phase (Title III Engineering) is controlled through inspection, testing, assessment, and acceptance activities - the final process for assuring that the systems and documentation are consistent and match the requirements. Formal procedures (see Section 4.3) governing these activities, along with the product specifications are released under configuration control. Verification records that result from this quality assurance/control process are also reviewed and accepted. 
All documents relating to Project baselines and configuration management processes, whether approved or disapproved, ultimately reside in the NIF Product Data Management (PDM) system and the NIF Quality Assurance (QA) file.

\subsection{Change Implementation}

The change control process provides for technical, scope, cost, and schedule review of proposed changes. Upon completion of the necessary reviews disposition actions are documented which provide instructions for implementation of approved changes.

Change implementation provides for verification that the physical and functional characteristics of the configuration items conform to the technical documentation and all associated baseline documentation impacted is updated.

\subsection{Procedures}

The performance standards established by the NIF Project to control the Project configuration include procedures for individual activities that comprise configuration management. In some cases, these are established and implemented via the Project Control Manual. ${ }^{1}$ Other procedures will be established by subtier organizations or subcontractors (via subcontract) as required by the NIF Project QA Program Plan. ${ }^{8}$ These procedures are reviewed and approved by the Project to assure their consistent compliance with the Project's requirements.

The NIF Project procedures related to configuration management are identified in Figure 1. The Project technical baseline is established according to:

- Procedure 5.1, Title II Design Review12

- Procedure 6.1, Preparation and Control of System Design Requirements 13

- Procedure 6.2, Preparation and Control of Interface Control Documents ${ }^{14}$

- Procedure 6.3, Engineering Drawing Standards and Control ${ }^{15}$

Revisions to the technical baseline are controlled by:

- Procedure 1.7, Project Change Control ${ }^{3}$

- Procedure 6.4 Engineering Change Requests 4

- Procedure 6.7, Control of Design Documents ${ }^{16}$

\subsection{Interface Control}

Interfaces between NIF systems are controlled through the use of ICDs on which essential data is recorded for use by the designers responsible for the systems on both sides of interfaces. Revisions to ICDs are controlled through the ECR process. The SI Manager coordinates the interface control process and resolves disagreements at interfaces. 


\subsection{Data Management}

\subsection{Configuration Data Management}

The NIF Project utilizes a specialized commercial PDM system for its configuration management and engineering change control processes. The software for this system is located on a server that interfaces with other Project and institutional databases. This system stores data in a relational database, utilizing the Project NWBS for primary organization and identification. The PDM system includes technical information associated with the Project technical baseline. The data is controlled in accordance with this CMP and data management and document control procedures. ${ }^{17}$

This system is used to record and report the current status of configuration items, technical documentation, and all proposed and approved changes throughout the life cycle of NIF. The workflow processes in the PDM system are used to track the implementation of approved changes to ensure that all affected documents and parts are updated and that all change directive instructions are followed. The system provides information on the current approved configuration of technical baselines and their associated documentation and pending changes against them. This information provides traceability of change proposals and historical information on all serialized configured items. Chronological records of changes and reports can be prepared for a configuration item or baseline document.

\subsection{Reporting}

The NIF Project Office collects, integrates, and maintains information for reporting Project progress, including factual statistics on accomplishments, work in progress, variance between plans and performance, and work plans and forecasts for the next reporting period. Project control and reporting is closely integrated with the performance measurement and baseline change control processes and provides for analysis of status and variance on a monthly basis. Reporting requirements are described in the $\mathrm{PEP}^{2}$ and are accomplished through the Project's performance measurement and reporting procedures. 


\subsection{Assessments and Validation}

\subsection{Design Assessments}

At every stage of activity, the Project implements a series of checks and balances to assure that the design is adequate and accurate and that the facilities and equipment resulting from implementation of the design meet specifications and will achieve the objectives identified in approved requirements documents.

This is accomplished during Title I and II Design by the succession of assessments, such as the internal design reviews and independent design reviews performed in accordance with established procedures. These assessments include, but are not limited to the control of design requirements and ICDs, the generation and review of design documents, system-wide design reviews, constructability and operability reviews, and other independent quality assessments. The safety and environmental assessments are accomplished and documented in a series of DOE-concurred (NIF Preliminary Hazards Analysis, ${ }^{18}$ NIF Preliminary Safety Analysis Report, ${ }^{19}$ Final Safety Analysis Report, 20 etc.) safety documents and DOE-prepared (Preliminary Environmental Impact Statement, ${ }^{21}$ NIF Mitigation Action Plan, 22 etc.) environmental documents.

\subsection{Physical Configuration Assessments}

During fabrication, construction, and installation activities, the facilities and equipment are qualified through the aggregate process controls involved in ensuring compliance with requirements established in the drawings and specifications. These include both NIF Project controls and Project-approved subcontractor procedures, such as:

- Qualification of suppliers.23

- Procurement controls. $23-25$

- Production process controls (requirements defined by the Project in subcontracts and documented by subcontractors in submittals). ${ }^{25}$

- Qualification of craftspersons. ${ }^{26}$

- Inspection methods (documented in specifications).

- Destructive and nondestructive testing.

- Functional inspections.

- Acceptance testing. ${ }^{27}$

- Nonconformance reporting and corrective action processing. ${ }^{28}$

- Quality assessments.29,30

Documentation and verification by NIF Project personnel of activities such as those cited above provide confidence that there is consistency between the documented technical baseline and the actual physical configuration. Discovery of items not in compliance with requirements triggers the nonconformance reporting and corrective action process. 28 
Ultimately, the "as-built" configuration of the NIF Project and all its components is recorded in the NIF PDM system by the approved documentation resulting from each of the activities discussed in this CMP.

\subsection{References}

\subsection{Developmental References}

1. DOE Order 4700.1, Chapter III, Part C, "Configuration Management."

2. DOE Order 430.1, Guide PMG 10, Project Execution and Engineering Management Planning.

3. DOE Good Practice Guide, CPG-FM-012, Configuration and Data Management

\subsection{Cited References}

1. NIF Project Control Manual, CD-027.

2. U.S. DOE NIF Project Execution Plan, UCRL-ID-126525.

3. NIF Procedure 1.7, Baseline Change Control, NIF-0003790.

4. NIF Procedure 6.4, Engineering Change Requests, NIF-0003132.

5. NIF Conceptual Design Report, UCRL-PROP-117093.

6. NIF Title III Engineering Plan, NIF-0010448-0A.

7. Justification of Mission Need, Appendix A Vol. 1 Bk. 1 of the NIF CDR (UCRL-PROP-117093).

8. NIF Quality Assurance Program Plan, NIF-0000518.

9. Conceptual Design Scope and Plan, NIF-93-043.

10. Title I Design Plan, NIF-96-650.

11. Title II Design Plan, NIF-0001249.

12. NIF Procedure 5.1, Engineering Design Reviews.

13. NIF Procedure 6.1, Preparation and Control of System Design Requirements, NIFLLNL-93-251, L-16551-2.

14. NIF Procedure 6.2, Preparation and Control of Interface Control Documents, NIFLLNL-93-252, L-16522-1.

15. NIF Procedure 6.3, Engineering Drawing Standards and Control, NIF-0002034.

16. NIF Procedure 6.7, Control of Design Documents.

17. NIF Product Data Management System Procedures Manual, NIF-0003739.

18. NIF Preliminary Hazards Analysis, UCRL-ID-116983.

19. NIF Preliminary Safety Analysis Report, UCRL-ID-123759.

20. NIF Final Safety Analysis Report, in progress.

21. Preliminary Environmental Impact Statement (PEIS) for Stockpile Stewardship and Management, DOE/EIS-0236.

22. NIF Mitigation Action Plan, NIF-0001726.

23. NIF Procedure 7.1, Supplier Qualifications, NIF-0001014.

24. NIF. Procedure 7.4, Special Equipment Procurement, NIF-0003695. 
25. NIF Procedure 7.5, Subcontract Administration, NIF-0015471.

26. NIF Procedure 7.3, Vendor Surveillance, LLNL-96-398, L-22051-1.

27. NIF Procedure 8.3, Preparation and Standard Content for Acceptance test Procedures, NIF-0004043.

28. NIF Procedure 3.2, Nonconformance Reporting, NIF-0011576.

29. NIF Procedure 9.2, Management Assessments, NIF-0000967.

30. NIF Procedure 10.1, Independent Assessments, NIF-0000281. 